\title{
A TRANSFORMAÇÃO DA EDUCAÇÃO EM MERCADORIA NO BRASIL
}

\author{
Romulaldo Portela de Oliveira*
}

RESUMO: O presente artigo apresenta pesquisa que estuda as consequências perceptíveis do processo de penetração dos fundos financeiros na educação superior no Brasil e, posteriormente, a emissão de ações de instituições de ensino diretamente na bolsa de valores. Entre os resultados observados encontra-se o rápido crescimento das instituições que adotaram tal estratégia. A forma mais visível desse crescimento é a compra de outras instituições e seu aperfeiçoamento, por meio da implantação de uma gestão mais profissionalizada. Tal processo tem propiciado o crescimento acelerado de algumas instituições, generalizando a educação como uma mercadoria, assim como a tendencial oligopolização da oferta. Conclui-se afirmando que é cabível falar-se em uma financeirização da educação, posto que é o setor financeiro que assume a hegemonia na educação privada no país.

Palavras-chave: Educação e globalização. Educação como mercadoria. Financeirização da educação. Mercado educacional. Educação para o lucro.

\section{THE TRANSFORMATION OF EDUCATION INTO COMMODITY IN BRAZIL}

ABSTRACT: This paper presents a research on the noticeable consequences of the supply of private equities and venture capital in Brazilian Higher Education and of the subsequent going public of many teaching institutions. These are growing fast, mainly through the purchase of other schools, whose administration is professionalized. Such process has generalized

Doutor em Educação e professor da Faculdade de Educação da Universidade de São Paulo (USP). E-mail: romualdo@usp.br 
both education as a commodity and the oligopolization of provision. It is thus possible to conclude that education has been financialized, since private education is nowadays hegemonic in Brazil.

Key words: Education and globalization. Education as a commodity. Financialization of education. Educational market. For profit education.

$\mathscr{P}$

odem ser identificadas quatro consequências da globalização para a educação, todas elas eivadas de tensóes e contradições: a) a crescente centralidade da educação na discussão acerca do desenvolvimento e da preparação para o trabalho, decorrente das mudanças em curso na base técnica e no processo produtivo; b) a crescente introdução de tecnologias no processo educativo, por meio de softwares educativos e pelo recurso à educação a distância; c) a implementação de reformas educativas muito similares entre si na grande maioria dos países do mundo; d) a transformação da educação em objeto do interesse do grande capital, ocasionando uma crescente comercialização do setor.

Nesta última dimensão, tem se dedicado bastante atenção ao debate em curso na Organização Mundial do Comércio/Acordo Geral de Tarifas e Comércio (OMC/GATT), acerca da conceituação da educação como um bem de serviço. A aprovação de tais acordos faria com que a educação passasse a ser regida pelas normas que se aplicam à comercialização de serviços em geral (cf. Dias, 2003, 2004; Dourado, 2002; Siqueira, 2005; Rikowski, 2003; Kelk \& Worth, 2002). Em consequência, terse-ia, além da ampliação da mercantilização na área, a internacionalização da oferta, com a penetração de grandes corporações multinacionais em países menos desenvolvidos. ${ }^{1}$ Entretanto, mesmo sem a aprovação de tais acordos, a educação tem se transformado, crescentemente, em mercadoria. Instituições lucrativas crescem a olhos vistos, assim como a internacionalização da oferta (cf. Altbach, 2000, 2002; Balan, 1990, 1993, 2000; Callan, 1997; Carlson, 1992; Morey, 2001). Nas singelas palavras de Angel Gurria, secretário geral da OECD, em manifestação realizada em Lagonissi, Grécia, em 28/06/2006, ao encerrar a conferência de Ministros de Educação daquela Organização: "A educação é hoje uma mercadoria negociável. Tornou-se exportável, portável e negociável”. 2 
Este texto reflete sobre esse processo, tomando como referência o caso brasileiro, e indaga que alternativas têm disponíveis os que entendem ser a educação um bem público e não uma mercadoria (Grace 1994; Noble, 2001; Hill \& Kumar, 2008).

No Brasil, o processo de desenvolvimento de um setor empresarial na educação é antigo, remontando, pelo menos, ao período da ditadura militar. Entretanto, isso era dissimulado, pois a legislação proibia que as instituiçôes de ensino, "pela sua natureza", dessem lucro. Apenas com a promulgação da Constituição de 1988 é que se explicitou a possibilidade de existência de escolas com fins lucrativos. A posterior regulamentação desse dispositivo na Lei de Diretrizes e Bases e na legislação complementar acelerou o seu crescimento.

Além da oferta de vagas, presenciais ou a distância, tanto na educação básica quanto, em maior escala, na superior, difundiram-se outras atividades comerciais. No ensino básico, cresceu a venda de materiais pedagógicos e "pacotes" educacionais, que incluem aluguel de marca, pelo mecanismo de franquias, avaliação e formação em serviço do professor. Tais atividades são desenvolvidas por algumas das grandes redes de escolas privadas, como os Cursos Osvaldo Cruz (COC), Objetivo, Positivo e Pitágoras. Mais recentemente, esse grupo de instituições tem avançado sobre os sistemas públicos de educação básica, vendendo materiais apostilados para redes municipais e estaduais, tendo os mesmos avaliados no âmbito do programa nacional do livro didático (PNLD). Ainda, em São José dos Campos (SP), com financiamento do Instituto EMBRAER, o Grupo Pitágoras desenvolveu um modelo de gestão do conjunto da rede municipal de ensino que o Instituto EMBRAER também já está aplicando em Sorocaba (cf. Silva, 2008). Passa-se, assim, da venda de materiais educativos para a definição da gestão do sistema público de ensino. Neste caso, assim como o programa desenvolvido pelo Instituto Ayrton Senna, sem acumulação de capital (cf. Adrião \& Peroni, 2008; Peroni, 2008). De todo modo, esse modelo de parceria permite que isso venha a acontecer. Tomando como referência os Estados Unidos, a gestão nãoestatal pode ser alvo da ação comercial, como ocorre em parte das escolas charter. Naquele país, a Edison Schools, entre outras, instituição privada com fins lucrativos, tem se dedicado a gerir escolas públicas em diferentes partes do país (cf. Saltman, 2005).

No ensino superior, o fenômeno é mais complexo. Observa-se o aumento da demanda, resultante da regularização do fluxo no ensino 
fundamental e do subsequente crescimento do ensino médio. Ao mesmo tempo, mantém-se a crônica dificuldade de se implementar uma política pública consistente, que permita expandir a oferta de modo a competir quantitativamente com a iniciativa privada. Esse conjunto de elementos criou um próspero e afluente mercado, cuja faceta mais importante refere-se à penetração do capital financeiro na educação e a consequente internacionalização da oferta educacional. Ainda que este texto concentre-se na questão da oferta educacional por parte de instituições lucrativas, mencione-se o crescimento de serviços auxiliares, como o das consultorias. Estas se dedicam a atividades diversas como elaboração de planos estratégicos, reengenharia institucional, elaboração de projetos de curso, programas de auto-avaliação, marketing institucional, desenvolvimento de sistemas próprios de crédito educativo etc. Há várias consultorias estabelecidas no mercado, sendo as mais conhecidas a $P$. $R$. Souza Consultores, do ex-ministro da Educação e atual secretário estadual de Educação de São Paulo, Paulo Renato Souza, a Lobo \& Associados, do ex-reitor da Universidade de São Paulo, Roberto Leal Lobo e Silva Filho, a CM consultores e a Hoper Educacional.

\section{Os fundos de Private Equity e a educação superior}

A primeira manifestação do que hoje se observa foi o estabelecimento, em 2001, de parceria entre o Grupo Pitágoras, de Minas Gerais, e a Apollo internacional. Na descrição apresentada no sítio eletrônico da primeira instituição, informa-se que:

A Faculdade Pitágoras surgiu da vocação de duas instituições para implementar uma educação superior de qualidade. De um lado, o Grupo Pitágoras, a terceira maior rede privada de ensino do país, com seus mais de 150.000 alunos e uma experiência que vem acumulando êxitos desde 1966. Do outro, a Apollo International, que adaptou, especialmente para a Faculdade Pitágoras, a metodologia da inovadora Universidade de Phoenix, EUA, mantida pelo Grupo Apollo - fundado em 1976 e hoje com 150.000 alunos. Essa parceria de sucesso garante formação profissional com padrão internacional, voltada para um mundo competitivo, globalizado e mutante. ${ }^{3}$

Essa parceria foi desfeita em 2006, quando o Grupo Pitágoras comprou a parte do investidor internacional. 
Ainda nos anos de 1990, fundos de investimento privado, os private equity, passaram a investir em educação, particularmente na educação básica. Segundo informações coletadas no sítio da Associação Brasileira de Private Equity e Venture Capital (ABVCAP):

Ao contrário dos fundos de renda variável (ações) convencionais, os fundos de venture capital e private equity são normalmente estruturados através de "condomínios fechados", ou seja, seus investidores subscrevem as quotas no início do fundo e não há possibilidade de resgate intermediário, pois os quotistas só recebem o capital na ocasião do desinvestimento/venda do fundo nas empresas da carteira, tipicamente de 5 a 10 anos após o início do fundo. Enquanto o venture capital está relacionado a empreendimentos em fase inicial, o private equity está ligado a empresas mais maduras, em fase de reestruturação, consolidação e/ou expansão de seus negócios. A essência do investimento está em compartilhar os riscos do negócio, selando uma união de esforços entre gestores e investidores para agregar valor à empresa investida. Os investimentos podem ser direcionados para qualquer setor que tenha perspectiva de grande crescimento e rentabilidade no longo prazo, de acordo com o foco de investimentos definido pelos investidores ou fundos. (Disponível em: <www.abvcap.com.br>, acesso em: 27 jun. 2009)

A ação desses fundos foi responsável pela grande concentração de matrículas, particularmente no ensino fundamental e médio, ao induzir a adoção de franquias das grandes redes, chegando atualmente a representar mais do que $30 \%$ da matrícula no setor privado nessas etapas da educação básica. ${ }^{4}$ No início desta década, ao se identificar que o setor de educação superior sofreria rápida expansão, a atenção dos fundos de investimento voltou-se para essa área, ocasião em que foram constituídos os primeiros fundos de investimento exclusivamente direcionados à educação. Esses fundos têm condições de injetar altas quantias em empresas educacionais, ao mesmo tempo em que empreendem ou induzem processos de reestruturação das escolas nas quais investem, por meio da redução de custos, da racionalização administrativa, em suma, da "profissionalização" da gestão das instituições de ensino, numa perspectiva claramente empresarial. Essa perspectiva racionalizadora é fundamentalmente orientada para a maximização de lucros, chegando ao paroxismo em algumas situações. Cite-se um exemplo. Segundo informação veiculada pela Hoper Educacional: 
A Hoper Consultoria Acadêmica desenvolveu um modelo inovador de redução de custos da atividade fim de uma instituição de ensino, com base na utilização de $20 \%$ da carga horária do curso com atividades nãopresenciais. O modelo utilizado pela Hoper não se utiliza de disciplinas a distância, mas sim de uma metodologia interdisciplinar, que proporciona uma economia em maior escala do que a obtida com a substituição de disciplinas, bem como um maior ganho na qualidade acadêmica do curso. (Disponível em: <www.hoper.com.br>, acesso em: 27 jun. 2009)

Traduzindo, juntam-se classes para atividades de estudo. Como o pagamento dos professores é por hora-aula, dependendo do número de classes que são agrupadas, a economia pode ser intensa. Professores de algumas dessas instituições que entrevistei me informaram que elas realizam procedimentos similares de economia. Além dessa de estudos conjuntos na biblioteca, pode-se utilizar de atividades de instrução programada nos laboratórios de informática, contabilizadas como aula na grade curricular, e o engenhoso mecanismo da "aula fictícia". Os professores contratados por hora-aula ganham adicional noturno após as 22 horas. Assim, encerram-se as atividades com os professores nesse horário, ainda que na grade curricular conste mais uma aula. Nesse caso, ou os alunos realizam estas atividades de laboratório de informática e biblioteca, ou simplesmente são dispensados.

São resultantes da ação desses fundos as duas transaçôes comerciais que podem ser consideradas deflagradoras das mudanças vividas pelo ensino superior privado nos últimos anos.

A primeira delas refere-se à aquisição, em dezembro de 2005, da Universidade Anhembi-Morumbi, por parte do grupo americano Laureate. O Banco Pátria, administrador do principal fundo de investimentos em educação no país, responsável pela definição da estratégia de negócios da Anhanguera Educacional e proprietário de parte do seu capital, foi o responsável pela reestruturação organizacional da AnhembiMorumbi para sua venda. Manifestou-se sobre esta aquisição, na ocasião, nos seguintes termos:

A aquisição do controle acionário da universidade paulista Anhembi Morumbi pelo grupo americano Laureate, em dezembro, representou muito mais que um bom negócio para o arquiteto Gabriel Monteiro Rodrigues, de 73 anos, fundador da instituição. Com a venda, fechada por 165 milhões de reais, pela primeira vez uma instituição estrangeira 
passou a mandar em uma universidade no Brasil, um marco da entrada do capital internacional num setor da economia que tem aumentado exponencialmente de tamanho. No ano passado, somente os cursos universitários privados movimentaram algo em torno de 15 bilhōes de reais, ou $50 \%$ mais que três anos atrás. A injeção de recursos de um grupo do porte do Laureate, com universidades espalhadas por 15 países, deve dar novo fôlego a esse mercado. De acordo com os planos do Laureate, $100 \%$ das ações da Anhembi Morumbi serão adquiridas pelos americanos até $2013 .^{5}$

A segunda, ainda mais impactante, foi a aquisição de $70 \%$ do controle da Anhanguera Educacional, um conglomerado de escolas superiores do interior do estado de São Paulo, com mais de 20 mil alunos em quatro faculdades e um centro universitário, por parte de um fundo de investimentos, administrado pelo Banco Pátria, que contou, inclusive, com aporte de doze milhôes de dólares do International Finance Corporation (IFC), braço empresarial do Banco Mundial (cf. O Estado de S. Paulo, 29 jul. 2006).

A notícia do investimento do IFC apareceu no seu press release, ${ }^{6}$ nos seguintes termos:

Washington, DC, 27 de junho de 2006 - O International Finance Corporation (IFC), braço do setor privado do Grupo Banco Mundial, anunciou hoje um financiamento de US\$12 milhôes para o Fundo de Educação para o Brasil - Fundo de Investimento em Participações (FEBR). O empréstimo do IFC será usado para financiar a expansão de uma instituição de educação pós-secundária, a Anhanguera Educacional (AES), que oferece educação de boa qualidade para alunos de baixa renda.

A Anhanguera Educacional é uma instituição com fins lucrativos em rápida expansão no Brasil, que tem por foco os alunos de baixa renda de cidades menores dentro do estado de São Paulo. Atualmente, a AES dirige dez campi em oito cidades, oferecendo cursos de graduação e pós-graduação para mais de 20.000 alunos. $^{7}$

As escolas vão à bolsa de valores

O episódio seguinte foi o lançamento, em fevereiro de 2007, de ações da Anhanguera Educacional na Bolsa de Valores de São Paulo, seguida pela Estácio de Sá, Kroton Educacional, do Grupo Pitágoras e 
pela Sociedade Educacional Brasileira (SEB), controladora do COC. Segundo informação veiculada pela publicação Retratos do Brasil, juntas, estas vendas de ações captaram R \$ 1,9 bilhão, em 2007-2008, e grande parte das mesmas foi comprada por estrangeiros (cf. Retratos do Brasil, n. 13, ago.-set. 2008).

Em seguida, sucederam-se os processos de compra de outras instituições. Ainda que esta não seja uma coleta exaustiva, dão uma dimensão do que está ocorrendo.

A Anhanguera comprou as seguintes instituições:

a) Em novembro de 2006, o ILAN, mantenedor da Faculdade Latino-Americana ("FLA"), localizada em Anápolis, no estado de Goiás, por R\$29,4 milhões;

b) Em dezembro de 2006, as Faculdades Integradas de Jacareí e a Faculdade Maria Augusta, mantidas pela Sapiens e Jacareiense, localizadas na cidade de Jacareí, por $\mathrm{R} \$ 3,715$ milhões;

c) Em fevereiro de 2007, o Centro Hispano-Brasileiro, mantenedor da UNIBERo, localizada na cidade de São Paulo, estado de São Paulo, por R \$ 15,97 milhões;

d) Em março de 2007, a União Fênix de Educação e Cultura, mantenedora das Faculdades Fênix de Bauru (FAFEB) e do Instituto Superior de Educação Fênix (ISEFEB), por R\$ 6,5 milhôes;

e) Em abril de 2007, as Faculdades Integradas da Zona Oeste (FIzO), por R \$ 18,2 milhões;

f) Em julho de 2007, a Sociedade Educacional Noiva do Mar, mantenedora da Faculdade Atlântico Sul, de Pelotas (RS), e da Faculdade Atlântico Sul, de Rio Grande (RS), por R\$16,84 milhōes;

g) Em outubro de 2007, a Universidade Regional do Pantanal (UNIDERP), de Campo Grande (MS) e mais cinco instituições do Grupo Pedro Chaves Santos Filho, de Mato Grosso do Sul, as Faculdades Integradas de Ponta Porã, Faculdades Dourados, Instituto de Ensino Superior de Dourados, Centro Universitário de Campo Grande e as Faculdades Integradas de Rio Verde, por R\$246,8 milhões; 
h) Em dezembro de 2007, o Instituto de Ensino Superior Senador Fláquer, de Santo André (SP), sociedade mantenedora do Centro Universitário de Santo André (UniA), por R \$ 59,9 milhôes;

i) Em fevereiro de 2008, a Instituição Educacional S/S Ltda. (Educar), sociedade mantenedora do Instituto de Ensino Superior de Joinville (IESVILLE), da Faculdade de Tecnologia IESVILLE (FATI), da Faculdade de Tecnologia São Carlos (FATESC), do (Instituto Superior de Educação de Santa Catarina (ISEC), da Faculdade de Tecnologia de Jaraguá do Sul (FATEJ) e do Instituto Tecnológico de Educação Superior e Pesquisa de Santa Catarina Ltda. (INTESC), em Santa Catarina, por R \$ 30 milhões;

j) Em fevereiro de 2008, a Sociedade Educacional Garra Ltda., mantenedora das Faculdades Planalto (FArplan), em Passo Fundo (RS), por R \$10,3 milhóes;

k) Em fevereiro de 2008, a Sociedade Educacional de Ensino Superior do Lago, mantenedora da Faculdade de Negócios e Tecnologia da Informação (FACNET), do Distrito Federal, por R \$ 20,5 milhões;

1) Em maio de 2008, a Sociedade Brasileira de Ensino Superior, mantenedora da Faculdade Brasileira de Ciências Exatas, Humanas e Sociais e da Faculdade de Tecnologia (FABRAI), por R\$ 10,4 milhões;

m) Em maio de 2008, a Sociedade Educacional Sul Sancaetanense, mantenedora da Faculdade Editora Nacional (FAENAC), de São Caetano do Sul, por R\$ 34 milhões;

n) Em maio de 2008, a Sociedade de Ensino Superior Itapecerica da Serra SS Ltda., mantenedora da Faculdade Regional de Itapecerica da Serra (FRIS), por R \$ 3,5 milhões

o) Em junho de 2008, o Centro de Ensino Superior de Rondonópolis (CESUR), Mato Grosso, por R\$ 13,7 milhões;

p) Em julho de 2008, a Instituição de Ensino Superior de Sertãozinho, mantenedora da Faculdade de Sertãozinho (FASERT-SP), por R\$ 2,6 milhões; 
q) Em setembro de 2008, a Sociedade Brasil Central de Educação e Cultura (SBCEC), mantenedora de seis instituições de ensino denominadas Faculdade JK, de Brasília, por R\$31,3 milhôes;

r) Em setembro de 2008, o Centro de Ensino Unificado de Taguatinga, mantenedor da Faculdade Santa Terezinha, por $\mathrm{R} \$ 5,3$ milhões;

s) Em setembro de 2008, a Pioneira Educacional Ltda., mantenedora da Faculdade Taboão da Serra, do Cursinho Universitário Taboão da Serra, do Colégio Universitário de Taboão da Serra, do Colégio Universitário de Taboão Ensino Fundamental e Escola de Educação Infantil Universitário Junior Taboão da Serra. O valor total do negócio foi de R $\$ 71,75$ milhões, sendo $\mathrm{R} \$ 32,55$ milhões referentes à aquisição da operação de ensino superior, $\mathrm{R}$ \$ 6,7 milhões referentes à aquisição da operação do colégio e cursinho, e R $\$ 32,5$ milhões referentes à aquisição do imóvel operacional;

Em 2008, anunciou a criação da Escola Superior de Administração Educacional (ESADE), a primeira escola corporativa do setor de educação. A nova escola é uma parceria com a Fundação Dom Cabral, cujo objetivo é oferecer cursos de gestão e qualificação a diretores, docentes e todo o quadro de funcionários do holding. Os investimentos chegaram a $\mathrm{R} \$ 1,5$ milhões. Além disso, em agosto de 2008, adquiriu $30 \%$ da rede de ensino profissionalizante Microlins, com opção de compra do capital total a partir de 2010 , por $\mathrm{R} \$ 25,5$ milhôes, e a rede Luiz Flávio Gomes de ensino a distância, em outubro de 2008, por $\mathrm{R} \$ 180$ milhões, $\mathrm{R}$ \$ 80 milhões à vista e $\mathrm{R} \$ 100$ milhões em 2013.

A Estácio de Sá adquiriu as seguintes instituiçôes:

a) Em agosto de 2007, o IREP, Sociedade de Ensino Superior, Médio e Fundamental Ltda. e da Faculdade Radial de Curitiba Sociedade Ltda., mantenedoras do Centro Universitário Radial, contando com 6 campi na cidade de São Paulo, 1 campus na região do ABC Paulista e 1 campus em Curitiba, por $\mathrm{R} \$ 55,7$ milhões; 
b) Em fevereiro de 2008, a Sociedade Interlagos de Educação e Cultura, mantenedora da Faculdade Interlagos (FINTEC), por R\$ 6,3 milhōes; da Sociedade Abaeté de Educação e Cultura Ltda., sociedade controladora do Instituto Euro-Latino-Americano de Cultura e Tecnologia Ltda., mantenedor da Faculdade EUROPAn, pelo valor total de R 8.352 milhões; e da Faculdade Brasília de São Paulo Ltda., pelo valor total de $\mathrm{R} \$$ 2.235 milhões;

c) Em junho de 2008, a União Cultural e Educacional Magister Ltda. (uniCEM), mantenedora da Faculdade Magister, instituição com sede e 2 campi na cidade de São Paulo, por $\mathrm{R} \$ 4,3$ milhôes;

A Kroton, das Faculdades Pitágoras, comprou:

a) Em setembro de 2007, $80 \%$ da Sociedade Educacional e Cultural de Divinópolis Ltda., mantenedora das Faculdades Integradas do Oeste de Minas (FADOM), por R\$ 7,164 milhôes;

b) Em dezembro de 2007, a União Capixaba de Ensino Superior (UCES), em Vitória, Espírito Santo, por R \$ 2 milhôes;

c) Em dezembro de 2007, a Instituição Educacional Terra da Uva, mantenedora do Instituto Japi de Ensino Superior de Jundiaí, por R \$ 5,2 milhões;

d) Em janeiro de 2008, as Faculdades Integradas Padre Anchieta, de Guarapari (ES), por R \$ 4,6 milhóes;

e) Em março de 2008, a UNIMINAS, de Uberlândia (MG), por R\$ 22 milhôes.

f) Em abril de 2008, a Sociedade Unificada de Ensino Superior e Cultura (SUESC), do Rio de Janeiro, por R \$ 31,5 milhôes;

g) Em abril de 2008, a mantenedora da Faculdade UNILINHARES, situada na cidade de Linhares, no Espírito Santo, por R \$ 15 milhões; 
Em junho deste ano, a empresa global de private equity Advent International anunciou a assinatura de um acordo pelo qual a Pitágoras Administração e Participação (PAP), holding que detém 55\% das ações da Kroton, comprou, por R\$280 milhões, 50\% das ações do holding, passando a deter indiretamente cerca de $28 \%$ do capital total da Kroton. $^{8}$

O Sistema Educacional Brasileiro ( $\mathrm{SEB}$ ), proprietário do $\mathrm{COC}$ de Ribeirão Preto (sp), adquiriu o Grupo Dom Bosco, de Curitiba, em negociação avaliada em R $\$ 94,5$ milhões e, em julho deste ano, adquiriu o grupo Pueri Domus, por $\mathrm{R} \$ 41$ mihões.

Além destes, a Veris Educacional controla as Faculdades IBMEC de Brasília, Rio de Janeiro e Minas Gerais, a IBTA, as Faculdades Uirapuru, de Sorocaba (sP), e a METROCAMP, de Campinas. A Whitney International (Best Group) adquiriu 50\% das Faculdades Jorge Amado (BA), por R\$ 23,5 milhões. O Grupo Devry adquiriu a Faculdade Nordeste, de Fortaleza (CE). A Laureate, além da Anhembi-Morumbi, adquiriu a Universidade Potiguar (UNP), de Natal; a Business School São Paulo; o Centro Universitário do Norte (UNINORTE), no Amazonas, e a Escola Superior de Administração Direito e Economia (ESADE), no Rio Grande do Sul. O Grupo Educacional Cruzeiro do Sul - composto pela Universidade Cruzeiro do Sul (Unicsul), de São Paulo, e o Centro Universitário Módulo (unimódulo), de Caraguatatuba - adquiriu o Centro Universitário do Distrito Federal (UNIDF). O grupo Campos de Andrade, de Curitiba, que comanda quatro instituiçôes de ensino superior, três no Paraná e uma em Brasília, comprou a Universidade Ibirapuera, de São Paulo, a IUNI Educacional, proprietária da Universidade de Cuiabá, adquiriu a FACSUL, de Itabuna (BA), e a FACDELTA, de Salvador, por R \$29,4 milhões. As seguintes instituições financeiras compraram participaçóes em Instituições de ensino: a) A Moema Participaçôes, da GP Investimentos, maior gestor de recursos de terceiros do país, comprou 20\% da Estácio de Sá, por R\$ 259.330.720,00; b) O UBC Pactual comprou 38\% das Faculdades do Nordeste; c) O Cartesian Group comprou parte do Grupo NE, mantenedor das Faculdades Mauricio de Nassau (PE). O Capital Group adquiriu uma parte do Grupo Kroton.

Finalmente, em outro tipo de transação, em 29/06/2007, o portal Valor Econômico informou que o fundo de private equity Tarpon e a Escola de Administração de Empresas de São Paulo da Fundação 
Getúlio Vargas constituíram o primeiro "endowment fund" de uma instituição de ensino superior no Brasil. Trata-se de uma categoria de fundo que estabelece que os rendimentos resultantes de sua gestão sejam revertidos para o financiamento de uma organização, neste caso a FGV.

Essas transações revelam o ritmo de expansão das instituiçóes com fins lucrativos, particularmente aquelas suportadas por fundos de investimento e/ou açōes na bolsa de valores. Segundo informaçôes fornecidas pela KPMG Consultoria, em 2007 ocorreram 19 aquisiçôes e em 2008, de janeiro a setembro, 41. Neste ano, já ocorreram algumas, mas o ritmo diminuiu em função da crise mundial, ainda que algumas instituições anunciem possíveis aquisiçōes para o segundo semestre. ${ }^{9}$ De toda forma, em períodos de crise econômica, sabe-se que as instituições mais frágeis são mais abaladas, o que facilita ainda mais sua absorção pelos grupos maiores.

As dimensões a que essas instituições estão chegando podem ser exemplificadas pelo caso da Anhanguera. Em 31/12/2006, já possuía 13 unidades operacionais, cujo alunado médio era 24.527 e seis unidades em fase de implementação, com previsão de abertura durante o ano de 2007. É constituída hoje de três redes de ensino, composta por campi, pólos de ensino a distância e centros de treinamento profissional. Nos campi oferece desde cursos de curta duração em rotinas administrativas até cursos de pós-graduação, passando por mais de 90 modalidades de cursos de graduação nas áreas de administração, direito, engenharia, saúde e outras ciências sociais aplicadas. Segundo dados apresentados em seu informe aos acionistas, possuía, em 2008, 52 campi em 37 cidades, atendendo a 125 mil alunos. Em março deste ano, já anunciava 252.094 alunos e 53 unidades. Informou, ainda, possuir 774 pólos de ensino a distância e atender 93 mil alunos. Por fim, na modalidade de educação profissional, atende 500 mil alunos em 657 franquias, distribuídas por 377 cidades.

Finalmente, a informação mais emblemática deste processo talvez tenha sido a oferta para aquisição da UNIP-Objetivo, por R \$ 2,5 bilhôes, feita pela Apollo International, em julho de 2008. Apesar de João Carlos Di Gênio tê-la recusado, os americanos informaram que veriam uma forma de aumentá-la. Tomando-se a linguagem da área de administração, poder-se-ia afirmar que, nos tempos atuais, o Objetivo tornou-se um player menor (cf. Valor Econômico, 19 jun. 2008). 
Segundo dados divulgados pela revista Exame, em 22/12/2008, estima-se que o ensino privado movimente, por ano, $\mathrm{R} \$ 90$ bilhōes, o equivalente a aproximadamente $3 \%$ do PIB. Ainda não ultrapassa os gastos públicos em educação, mas é importante lembrar que, em 2004, movimentou $\mathrm{R} \$ 15$ bilhóes e este montante já era $50 \%$ maior do que em 2001. Ou seja, de 2001 a 2008 o setor do ensino privado aumentou seu movimento de capitais de $\mathrm{R} \$ 10$ bi para 90 ! Nenhum setor na economia brasileira cresceu tanto no período.

Esses exemplos evidenciam que a aprovação dos acordos da OMC não implicaria uma mudança de qualidade na situação vigente, apenas a aprofundaria, uma vez que parte importante do ensino privado no Brasil, como de resto em todo o mundo, já se encontra completamente na esfera do mercado.

O temor da internacionalização do mercado interno que adviria dos acordos também é infundado. Ela já ocorre, posto que a legislação brasileira não proíbe que capitais internacionais invistam em educação no país. De todo modo, tal debate é inócuo, uma vez que estes podem investir na bolsa de valores e as instituições educacionais podem lançar açóes na bolsa! Mesmo que vingasse a proposta formulada pelo MEC de limitar a participação estrangeira a $30 \%$ do capital total das escolas, isso seria contornado com a compra de ações na bolsa, onde não há limites.

Em escala mundial, o processo é similar. Segundo informaçōes constantes de trabalho de Savage (apud Feast \& Bretag, 2005, p. 64), o setor de educação internacional movimenta, anualmente, US \$ 2,2 trilhões, ${ }^{10}$ tornando a reflexão em torno da expansão dos interesses comerciais na área uma importante questão política e, obviamente, objeto de intensa pesquisa.

A educação como mercadoria oligopolizada

Estas dimensões evidenciam processo muito mais amplo de transformação do setor educacional em atividade mercantil. Da mesma forma, tal transformação é mundial, representando claramente uma das dimensões da globalização. As áreas em que isso ocorre vão da oferta direta de cursos, presenciais e a distância, à produção de materiais instrucionais, na forma de livros, apostilas e softwares, às empresas de 
avaliação, ou, mais precisamente, de medida em larga escala, às consultorias empresariais na área e até mesmo à ação de consultores do meio empresarial que assessoram tanto a inserção de empresas educacionais no mercado financeiro, quanto direcionam investimentos de recursos para a educação. São facetas de acentuada transformação do panorama educacional em escala mundial.

Em vista disso, coloca-se a questão: a educação transformou-se em mercadoria? Recorrendo a uma definição de mercadoria, apresentada em Bottomore (1998, p. 266), pode-se dizer que "mercadoria" é tudo que possa ser "comprado ou vendido" numa perspectiva de acumulação de capital. ${ }^{11}$ À luz dos dados aqui apresentados, resta pouca dúvida de que a educação tenha se transformado em importante mercadoria. A repetida afirmação de que educação não é mercadoria é mais a expressão de um desejo ou de uma bandeira de luta do que algo que se espelhe na realidade. Pode ser aceita apenas como um dever ser, como formulação programática. Na literatura encontramos intensa discussão nos países anglo-saxões, em fins dos anos de 1980, entre a concepção de educação como uma mercadoria, de um lado, e como um bem público, de outro ${ }^{12}$ (cf. Altbach, 2001).

Parece-me que reduzir o sentido social da educação aos interesses do lucro representa um empobrecimento tanto do conceito de educação, quanto de seu sentido para a coesão e viabilidade das sociedades. Nas palavras de Altbach (2002): "há valores do bem comum, com dimensão nacional e social, que devem ser protegidos e preservados em um ambiente educacional globalizado". ${ }^{13}$

Entretanto, não estamos frente a uma situação em que seja possível frear o avanço do mercado educacional por formulações compartilhadas por parte da sociedade. O fato é que, mesmo se afirmando, inclusive no texto constitucional brasileiro, que educação é um direito social e um dever do Estado, o mercado avança vorazmente.

As tentativas de impedir a mercantilização da educação por meio de proibiçôes legais mostram-se mais formais do que instrumento efetivo. Vide a antiga proibição das instituições educacionais auferirem lucro. É mais ou menos como proibir a circulação de uma mercadoria para a qual há demanda. A consequência é apenas o aparecimento de um mercado negro. Ou seja, viabilizam-se formas de burla ao dispositivo legal. 
Entretanto, mais do que sua transformação em mercadoria, o que estamos observando, no caso do ensino superior, é um processo intenso de concentração. Assim, é possível falarmos, também, em processo de oligopolização. Ou seja, o número de fornecedores tende a se concentrar ainda mais nos próximos anos e uma fatia significativa do mercado tende a ficar com os maiores grupos. Mantidas as condições atuais de sustentação exclusivamente por mensalidades, poucos serão os que conseguirão ocupar nichos específicos do mercado sem ser acossados pelas instituições maiores.

Finalmente, vamos recorrer ao conceito de financeirização, nos termos formulados por Chesnais (2007) e Harvey (2008), para entender o que se passa no setor:

Cada vez mais liberta das restrições e barreiras regulatórias que até então limitavam seu campo de ação, a atividade financeira pôde florescer como nunca antes, chegando a ocupar todos os espaços. Uma onda de inovações ocorreu nos serviços financeiros para produzir não apenas interligações globais bem mais sofisticadas, como também novos tipos de mercados financeiros baseados na securitização, nos derivativos e em todo tipo de negociação de futuros. (Harvey, 2008, p. 41)

É exatamente essa liberdade de trânsito do capital financeiro que permite sua avassaladora penetração no setor educacional brasileiro, fazendo com que sua ação seja o pólo dinamizador do setor, tornando-se, assim, hegemônico face aos capitais tradicionais da área. E, lembrando velha lição de Marx, para perceber a dinâmica capitalista é necessário olhar-se o setor capitalista mais desenvolvido.

$\mathrm{Na}$ medida em que as tentativas de limitar sua expansão, pela via da regulação ou restrições legais, me parecem fadadas ao fracasso, ainda que devam ser implementadas como forma de preservar condiçōes mínimas de funcionamento que não corrompam e desmoralizem completamente a natureza da atividade educativa na sociedade, entendo que só é possível limitar sua expansão a partir de uma ampliação da oferta pública, de modo a atender a parcelas substantivas da população e criar alternativas de atendimento em massa. Isto implica, portanto, um enfrentamento da complexa questão do equacionamento das condições de oferta pública, que abrange desde aspectos relativos à eficiência da gestão no âmbito dos serviços públicos, à diferenciação dos modelos de organização do ensino superior, à utilização das novas tecnologias da informação 
e as condições de financiamento do ensino superior. Para tal, será necessário implementar resoluta política de valorização do setor público. Entretanto, transformar tal formulação em política prática pressupóe superar desafios complexos, que se iniciam com a construção de uma estratégia comum de valorização do público. O problema é que longe estamos de conseguir estabelecer tal estratégia.

\section{Recebido e aprovado em agosto de 2009.}

\section{Notas}

1. Há também intenso debate sobre o que significaria a aplicação para o caso da educação de algumas das cláusulas desse acordo, como as da Nação mais favorecida e do Tratamento Nacional, que preconizam não se distinguir os diferentes provedores de serviço, sejam eles nacionais ou estrangeiros (artigos II e XVII, do GATT. Disponível em: <www.wto.org>. Acesso em: 20 jun. 2009).

2. Disponível em: <http://findarticles.com/p/articles/mi_kmafp/is_200606/ai_n16553287/>. Acesso em: 27 jun. 2009.

3. Disponível em: <http://www.faculdadepitagoras.com.br/conheca/parceiros.asp>. Acesso em: 15 fev. 2009.

4. A informação acerca do número de alunos atendidos, no setor privado, pelo mecanismo de franquia das grandes redes não é fácil. Encontrei apenas informações na grande imprensa, como a veiculada pela coluna de Antônio Góis, publicado na Folha de S. Paulo em 14/ 01/2002: "Segundo informações das próprias instituições, o número de alunos desses cinco grandes grupos (Positivo, Pitágoras, COC, Objetivo e Anglo) somados é de 1,3 milhão, o que corresponde a $31 \%$ do total de matrículas da rede privada nos ensinos médio e fundamental, de acordo com o Censo 2001 do Ministério da Educação".

5. Disponível em: <http://www.bancopatria.com.br/site/noticias.2005>. Acesso em: 14 ago. 2006.

6. Disponível em: <www.ifc.org>. Acesso em: 14 ago. 2006.

7. Antes do Brasil, o IFC investiu em educação privada do México, Chile, Turquia e Nigéria, entre outros.

8. Disponível em: <http://ultimosegundo.ig.com.br/economia/2009/06/25/fundo+advent+ compra+50+do+grupo+kroton+6949937.html>. Acesso em: 25 jul. 2009.

9. Disponível em: <www.kpmg.com.br>. Acesso em: 27 jun. 2009.

10. Estudos realizados em outros países analisaram a penetração, no setor educacional, de setores privados claramente orientados por uma lógica de acumulação de capital (Kinser \& Levy, 2005; Abbot, 2005; Saltman, 2005), havendo, dos dois lados do Atlântico, centros de pesquisa exclusivamente dedicados a analisar o impacto da crescente mercantilização do setor, ainda que este impacto, até o momento, seja maior nas Américas do que na Europa. Destaque-se entre estes o Center for Comparative and Global Studies In Education, da State University of New York at Buffalo (SUNY), coordenado por Bruce Johnstone, o

Educ. Soc., Campinas, vol. 30, n. 108, p. 739-760, out. 2009

Disponível em <http://www.cedes.unicamp.br> 
Center for International Higher Education (CIHE), do Boston College, coordenado por Philip Altbach, o National Center for the Study of Privatization in Education, do Teachers College da Columbia University, coordenado por Henry Levin, o Commercialism in Education Research Unit (CERU), da Universidade do Arizona, coordenado por Alex Molnar, nos Estados Unidos, e o Centro da Universidade de Bristol, coordenado por Roger Dale, entre outros.

11. Desenvolvendo a formulação: "A mercadoria tem, portanto, duas características: pode satisfazer a alguma necessidade humana, isto é, tem aquilo que Adam Smith chamou de valor de uso; e pode obter outras mercadorias em troca, poder de permutabilidade que Marx chamou de valor. (...) Como valores, as mercadorias são qualitativamente iguais e só diferem quantitativamente no montante de valor que encerram. Como valores de uso, as mercadorias são qualitativamente diferentes, já que cada produto é específico e não pode ser comparado a outro" (Bottomore, 1998, p. 266).

12. O trabalho de Valdemar Sguissardi (2008) é um dos primeiros entre nós a apresentar a extensão do fenômeno e suas características principais, buscando compreendê-lo teoricamente.

13. "In other words, there are values of the national and social common good that must be protected and preserved in a globalized educational environment".

\section{Referências}

ADRIÃO, T.; PERONI, V. (Coord.). Análise das conseqüências de parcerias firmadas entre municípios brasileiros e a Fundação Ayrton Senna para a oferta educacional. Rio Claro: UNESP, 2008. (Projeto de pesquisa).

ALTBACH, P.G. Private Prometheus: private higher education and development in the 21 st century. Westport, Conn: Greenwood, 2000. (Contributions to the study of education, n. 77).

ALTBACH, P.G. Knowledge and education as international commodities: the collapse of the common good. Current Issues in Catholic Higher Education, Washington, DC, n. 22, p. 55-60, 2002. Disponível em: <www.bc.edu/bc_org/avp/soe/cihe/newsletter/News28/text001.htm>. Acesso em: 25 jun. 2009.

BALÁN, J. Private universities within the Argentine higher educational system trends and prospects. Higher Education Policy, London, v. 3, p. 13-17, jun. 1990.

BALÁN, J. Governance and finance of national universities in Argentina: current proposals for change. Higher Education, Amsterdam, v. 25, n. 1, p. 45-60, 1993. 
BALÁN, J.; FANELLI, A.M.G. El sector privado de la educación superior: políticas públicas y sus resultados recientes en cinco países de América Latina. Buenos Aires: Centro de Estudios de Estado y Sociedad, 1993.

BOK, D. Universities in the marketplace: the commercialization of higher education. Princeton: Princeton University, 2003.

BOTTOMORE, T. Dicionário do pensamento marxista. Rio de Janeiro: Zahar, 1998.

CALLAN, P.M. Public and private financing of higher education: shaping public policy for the future. Phoenix: Oryx; American Council on Education, 1997.

CARLSON, S. Private financing of higher education in Latin America and the Caribbean. Washington, DC: World Bank, 1992. (Regional Studies Program Report, n. 18).

DIAS, M.A.R. Comercialização no ensino superior: é possível manter a idéia de bem público? Educação \& Sociedade, Campinas, v. 24, n. 84, p. 817-838, set. 2003.

DIAS, M.A.R. Dez anos de antagonismo nas políticas sobre ensino superior em nível internacional. Educação \& Sociedade, Campinas, v. 25, n. 88, p. 893-914, out. 2004.

DOURADO, L.F. Reforma do Estado e as políticas para a educação superior no Brasil nos anos 90. Educação \& Sociedade, Campinas, v. 23, n. 80 , p. 234-252, set. 2002.

GRACE, G. Education is a public good: on the need to resist to domination of economic Science. In: BRidges, D.; Mclaughlin, T.H. Education and the market place. London: Routledge, 1994. p. 126-137.

HILL, D.; KUMAR, R. Global neoliberalism and education and its consequences. London: Routledge, 2008.

KELK, S.; WORTH, J. Trading it away: how GATS threatens UK higher education. Oxford: People and Planet, 2002.

KELLY, K.F. Meeting needs and making profits: the rise of for-profit degree-granting institutions. Denver: Education Commission of the States, 2001. 
KINSER, K.; LEVY, D.C. The for-profit sector: Us patterns and international echoes in higher education. Albany: University of Albany, 2005. (prophe Working Paper Series, n. 5). Disponível em: <http:// www.albany.edu/dept/eaps/prophe>.

MARTINS, C.B. Ensino pago: um retrato sem retoque. São Paulo: Global, 1981.

MOLNAR, A. The commercial transformation of public education. Journal of Education Policy, London, v. 21, n. 5, p. 621-640, 2006.

MOREY, A. The growth of for-profit higher education. Journal of Teacher Education, Washington, DC, v. 52, n. 4, p. 300-311, 2001.

NAIDOO, R. Repositioning higher education as a global commodity: opportunities and challenges for future sociology of education work. British Journal of Sociology of Education, Oxfordshire, v. 24, n. 2, p. 249-259, 2003.

NAIDOO, R. Commodifying learning: pitfalls and possibilities. Reflections on Higher Education, v. 13, p. 50-61, 2004.

NEWTON, R.R. For-profit and traditional institutions: a comparison. International Higher Education, v. 27, 2002.

NOBLE, D.F. Digital diploma mills: the automation of higher education. New York: Monthly Review, 2001.

PERONI, V.M.V. O público e o privado na gestão e financiamento de sistemas educacionais públicos: um estudo dos programas da Rede Vencer. In: Albuquerque, M.G.M.T.; Farias, I.M.S.; Ramos, J.F.P. Política e gestão educacional: contextos e práticas. Fortaleza: UECE, 2008.

PINHEIRO, M.F. O público e o privado na educação: um conflito fora de moda? In: FÁvero, O. A educação nas constituintes brasileiras: 18231988. 2. ed. Campinas: Autores Associados, 2001. p. 293-302.

RIKOWSKI, G. Schools and the GATS enigma. Journal for Critical Education Policy Studies, v. 1, n. 1, mar. 2003.

RYAN, Y. Higher education as a business: lessons from the Corporate World. Minerva, v. 39, n. 1, p. 115-135, 2001. 
SALTMAN, K. The Edison schools: corporate schooling and the assault on public education. London: Routledge, 2005.

SCHWARTZMAN, J.; SCHWARTZMAN, S. O ensino superior privado como setor econômico. Trabalho realizado por solicitação do Banco Nacional de Desenvolvimento Econômico e Social (BNDES). Rio de Janeiro, 2002. (mimeo.).

SCHWARTZMAN, S. La universidad como empresa económica. Revista de Educación Superior, Mexico, v. 30, n. 117, p. 99-104, 2001.

SGUISSARDI, V. Modelo de expansão da educação superior no Brasil: predomínio privado/mercantil e desafios para a regulação e a formação universitária. Educação \& Sociedade, Campinas, v. 29, n. 105, p. 991-1022, dez. 2008.

SILVA, I.I. Estratégias municipais para a oferta da educação básica: análise da parceria público-privado no município de São José dos Campos. 2008. (Trabalho de conclusão) - Curso de Licenciatura e Bacharelado em Ciências, Universidade Estadual Paulista, Rio Claro.

SINCLAIR, M. Three futures for university provision: the social justice market, capitalism and private for-profit universities. Journal of Higher Education Policy and Management, Abingdon, v. 25, n. 2, p. 161-171, 2003.

SIQUEIRA, A.C. The regulation of education through the WTO/GATS. Journal for Critical Education Policy Studies, v. 3, n. 1, mar. 2005.

SORJ, B. O ensino público e o ensino privado no Brasil. Santiago: PREAL, 2000 .

TEMPLE, P.; WHITCHURCH, C. (Ed.). Universities in the marketplace. Manchester: Conference of University Administrators, 1992.

TOOLEY, J. The "neo-liberal" critique of state intervention in education: a reply to Winch. Journal of Philosophy of Education, London, v. 32, n. 2, p. 267-281, 1998.

TOOLEY, J. Should the private sector profit from education?: the seven virtues of highly effective markets. London: Libertarian Alliance, 1999. (Educational notes, n. 31). 
A transformação da educação em mercadoria no Brasil

TOOLEY, J. The global education industry: lessons from private education in developing countries. 2. ed. London: Institute of Economic Affairs, 2001. 